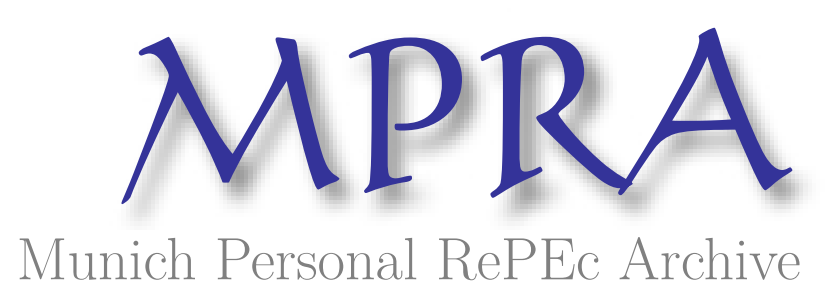

\title{
Reexamining the Empirical Relevance of Habit Formation Preferences
}

Cai, Zongwu and Liu, Xuan and Yang, Fang

3 April 2012

Online at https://mpra.ub.uni-muenchen.de/37817/

MPRA Paper No. 37817, posted 03 Apr 2012 19:47 UTC 


\title{
Reexamining the Empirical Relevance of Habit Formation Preferences
}

\author{
Zongwu Cai* Xuan Liu ${ }^{\dagger} \quad$ Fang Yang ${ }^{\ddagger}$
}

April 2, 2012

\begin{abstract}
We reexamine the empirical relevance of habit formation preferences with microdata on households' portfolio choices. We first derive the analytical solution to the risky asset share in a theoretical model with both habits and time-varying labor income. Our analytical results indicate that (1) for each household, there are two channels through which the risky asset share responds to wealth fluctuations, habits and household income; (2) across households, there are heterogenous responses through the habit channel: those who experience large negative income shocks reduce their share of risky assets; and (3) two potential mis-identification problems arise when both two channels and the heterogeneity are ignored. Contrary to the existing literature, our empirical results find positive evidence of habit formation preferences after correcting the two mis-identification problems.
\end{abstract}

Keywords: Habit formation; Micro data; Portfolio choice.

JEL classification: E21; E24; D91

*Department of Mathematics and Statistics, Department of Economics, University of North Carolina at Charlotte; WISE, Xiamen University, Fujian, China.

$\dagger$ Department of Economics, East Carolina University. Greenville, NC 27858. Email: liux@ecu.edu

${ }^{\ddagger}$ Department of Economics, BA 109, University at Albany, Albany, NY 12222. Email: fyang@albany.edu. URL: www.albany.edu/ fy 554862 . 


\section{Introduction}

Macroeconomic models with habit formation preferences have been used to explain a variety of dynamic asset pricing phenomena and macroeconomic facts, such as the equity premium puzzle [see, Campbell and Cochrane (1999), Boldrin et al. (2001), and others], the excess sensitivity of consumption to income [see, for example, Boldrin et al. (2001)], the equity home bias [see, among others, Shore and White (2002)], the hump-shaped response of aggregate variables to monetary shocks [Fuhrer (2000), Uribe (2002), Christiano et al. (2005)], and countercyclical markups [Ravn et al. (2006)]. Despite the mounting literature that uses habit formation, there are only a few papers that test the existence of habit formation from Micro-data.

The existing studies that test key theoretical implications from theoretical models with habits using Micro-data, find mixed evidence of habit formation preferences. For example, Dynan (2000) rejects habit preference using US consumption data. On the contrary, Ravina (2007) provides evidence of habit persistence in household consumption choices using a panel data of U.S. credit-card account holders. Carrasco et al. (2007) estimate the intra-temporal marginal rate of substitution using Spanish consumption panel data and find strong support of habit. Recently, Brunnermeier and Nagel (2008) investigate how households portfolio allocations change in response to wealth fluctuations and find negative evidence of habits.

In this paper, we reexamine predictions of habit formation preferences on households' portfolio choices with the Panel Study of Income Dynamics (PSID) data. We first build a discrete-time model of portfolio choice with habit and time-varying income from sources other than wealth (hereafter household labor income). Our emphasis on time-varying household income is simply motivated by the empirical facts of the PSID data. (1) All households in the PSID data received labor income. And (2) a large portion of households in the PSID data experienced large negative income shocks. For example, about 30\% households received income below $30 \%$ of their average income over time. Our theoretical model extends Brunnermeier and Nagel (2008) and considers the impact of time-varying household income 
on portfolio choice.

We derive the analytical solution to the risky asset share in our portfolio choice model with both time-varying household income and habits. Our close-form solution suggests that for each household, its risky asset share responds to wealth fluctuations through two channels: the habit channel and the household income channel. Under normal circumstances (for example, the household in our model does not experience large negative income shocks), the share will go up due to the existence of habits and go down in the presence of household income. Thus, a mis-identification problem may arise when the response due to both habits and household income is ascribed to the response due to habits. We call this an internal misidentification problem. The second bias arises due to the heterogeneity in households' income shocks. Specifically, households with large negative income shocks are likely to decrease their risky asset shares responding to wealth accumulations in the habit channel, while households without large negative income shocks will increase their risky asset shares when they become richer. Thus, habit formation preferences imply opposite relative risky aversion predictions across households. As a result, an external mis-identification problem may arise when estimating over samples in which heterogenous households are pooled together.

To facilitate the discussion, we define three different forms of habit formation preference implications (hereafter HFPI): the strong form, the semi-strong form, and the weak form. ${ }^{1}$ If the portfolio choice model with habits considers neither the aforementioned two channels for each household, nor the aforementioned heterogeneous responses through the habit channel across households, we label the key theoretical implication from such a model as the strong form of HFPI. The strong form implies that households will, unconditionally, increase their risky asset shares when their wealth increases, as is discussed in Brunnermeier and Nagel (2008). If the portfolio choice model with habits does consider the two channels but ignores the heterogeneity, we label the key theoretical implication from such a model as the semistrong form of HFPI. The semi-form implies that after controlling for the impact of household

\footnotetext{
${ }^{1}$ When a model imposes less restrictions, we say the derived theoretical implication is stronger.
} 
income, the response through the habit channel should be positive. At last, if the portfolio choice model with habits considers both the two channels and heterogeneity, we label the key theoretical implication from such a model as the weak form of HFPI. The weak-form implies that after controlling for the impact of household income and the impact of large negative income shocks, the response through the habit channel in the group in which households experienced large negative income shocks should be lower than that in the group in which households did not experience large negative income shocks.

We then empirically test the semi-strong form and the weak form of HFPI and compare the results with the strong form tested in Brunnermeier and Nagel (2008). We find positive evidence of the weak-form of HFPI and no evidence of the semi-form of HFPI. First, if the identification scheme builds on a model that does consider the two channels but ignores the heterogeneity so that the test corrects the internal but not the external mis-identification problem, our estimates are statistically insignificant. This contrasts strongly to Brunnermeier and Nagel (2008), who test the strong-form of HFPI and find negative responses. This comparison is in line with our theory, which states that controlling the impact of household income will increase the response. Second, if the identification scheme builds on a model that considers both the two channels and the heterogeneity so that the test corrects both the internal and the external mis-identification problems, our estimates are both economically and statistically significant, a finding which is clear evidence of habit formation preferences. In summary, our empirical results highlight the importance of incorporating time-varying income in a portfolio choice model.

The rest of the paper is organized as follows. Section 2 presents the model and provides testable implications. Section 3 briefly explains the data, variables and the sample selection. Section 4 presents the results on weak form of HFPI and Section 5 shows the results on semi-strong Form of HFPI. Section 6 concludes. 


\section{Model and Testable Implications}

The theoretical model is a highly stylized portfolio choice model with a time-varying household income flow and constant external habits. We consider the model for several reasons. First, it captures the realistic feature that the majority of the US households do receive time-varying household income. Second, the majority of modern macroeconomics models, if they assume habit formation preferences, contain these two elements. Third, the model delivers clear testable predictions on the targeted relationship between risky asset shares and wealth fluctuations.

\subsection{The Model}

In this economy, the household inherits wealth, $W_{t}$, from the last period, receives household income, $Y_{t}$, in the current period, and chooses consumption $C_{t}$ and the share of wealth $W_{t}-C_{t}+Y_{t}$ invested in the risky asset, $\alpha_{t}$, to maximize

$$
U=\mathbb{E} \sum_{t=0}^{\infty} \delta^{t} \frac{\left(C_{t}-X\right)^{1-\sigma}}{1-\sigma}
$$

where $\mathbb{E}$ denotes the unconditional expectation operator and $\delta$ denotes the subjective discount factor. $X$ denotes the external habit. ${ }^{2}$ The household receives time-varying household income in our model. This is different from Brunnermeier and Nagel (2008) in which there is no household income. To facilitate the discussion (in order to obtain the analytical solution), we impose the following restriction on household income:

$$
\left(Y_{t+1}-Y\right)=\kappa\left(Y_{t}-Y\right)+\eta_{t+1}
$$

\footnotetext{
${ }^{2}$ In the appendix, we show that under normal circumstances, time-varying external habits do not bring much additional insight about how habit formation preferences affect the relationship between risky asset shares and wealth fluctuations. Brunnermeier and Nagel (2008) show the similar conclusion in their appendix. For this very reason, we assume constant, instead of time-varying, external habits.
} 
where $Y$ denotes the steady state of household income. $\kappa$ is a parameter whose value is within $(-1,1)$. The innovation term, $\eta$, follows identical and independent normal distributions. Our specification may be restrictive in the sense that we assume an $\operatorname{AR}(1)$ process of $Y_{t}$. Nevertheless, such a process enables us, when there is no uncertainty, to derive a close-form solution, which will deliver clear theoretical predictions.

The household can invest in two securities: a risky asset with return $R_{t}$ and a risk-free asset with return $R_{f}$. As a result, the household's wealth in the beginning of period $t+1$ is given by

$$
W_{t+1}=\left(1+R_{p, t+1}\right)\left(W_{t}+Y_{t}-C_{t}\right)
$$

where $R_{p, t+1}=\alpha_{t}\left(R_{t}-R_{f}\right)+R_{f}$ denotes the return to the household's wealth portfolio.

Under the condition that expected return and the standard deviation are constant and there are no income shocks, i.e., $\eta_{t} \equiv 0$, the solution to $\alpha_{t}$ is given by:

$$
\alpha_{t}^{*}=\alpha\left[1-\frac{X-Y}{\left(W_{t}-C_{t}+Y_{t}+\frac{Y_{t}-Y}{Z+R_{f}}\right) R_{f}}\right]\left[1+\frac{Y_{t}-Y}{\left(W_{t}-C_{t}+Y_{t}\right)\left(Z+R_{f}\right)}\right]
$$

where $Z=\frac{1-\kappa}{\kappa}\left(1+R_{f}\right)$, and $\alpha$ denotes the solution of the risky asset share in the portfolio choice problem in Samuelson (1969). The derivation is in the appendix. Eq. (2.2) provides an analytical solution that enables us to discuss how the risky asset share responds to post consumption wealth and how household time-varying income and habits affect the response. Next, we discuss the role of household time-varying income and habits on the response of risky share to wealth shock.

\subsection{Two Channels and An Internal Mis-identification Problem}

For each household, its risky asset share responds to its wealth accumulation through two channels, the habit channel and the household income channel. The internal mis- 
identification problem arises when the response through two channels is ascribed as the response through the habit channel. To see this, we set $Y_{t} \equiv Y$ and Eq. (2.2) reduces to:

$$
\alpha_{t}^{*}=\underbrace{\alpha\left[1-\frac{X}{\left(W_{t}-C_{t}+Y\right) R_{f}}\right]}_{\text {The habit channel: }+}+\underbrace{\alpha\left[\frac{Y}{\left(W_{t}-C_{t}+Y\right) R_{f}}\right]}_{\text {The income channel:- }} .
$$

The sign "+" ("-") means that the risky asset share will increase (decrease) when the postconsumption wealth increases. It is clear that $\alpha_{t}^{*}$ respond to the change of $W_{t}-C_{t}$ in two channels: the habit channel ("+") and the income channel ("-"). One thing worth mentioning is even though $\alpha_{t}^{*}$ is decreasing in post consumption wealth through the second channel, $\partial \alpha_{t}^{*} / \partial Y$ is still positive: the higher household income the household has, the larger the $\alpha^{*}$ will be. In addition, even though adding a constant stream of household income in case of a constant habit is mathematically isomorphic (in terms of the asset allocation implications) to just reducing the habit by a constant, these are two quite different concepts and more importantly, ignoring the impact of household income will bias down the estimation of habit formation.

From Eq. (2.3), we obtain the following core regression equation:

$$
\Delta \alpha_{t}^{*} \approx(\rho-\theta Y) \Delta w_{t}+\varepsilon_{t}
$$

where $\Delta$ denotes the first-order difference, $w_{t} \equiv \log \left(W_{t}-C_{t}\right)$, and $\varepsilon_{t}$ follows identical, independent, normal distribution and is uncorrelated with $\Delta w_{t}{ }^{3} \rho$ is the parameter that catches the response of risky asset shares to wealth fluctuations through the habit channel. In the case of $Y_{t} \equiv Y$, we conclude that $X>0$ implies that $\rho>0$. That is to say, a positive estimate of $\rho$ suggests that habit formation preferences are in line with portfolio choice data. As is explained in Brunnermeier and Nagel (2008), an increase in wealth, for example, should lead to a temporary decrease in relative risk aversion and an increase of the risky asset share

\footnotetext{
${ }^{3}$ The derivation of Eq. (2.4) is in the appendix.
} 
if households have habit formation preferences. We conclude $\theta>0$ because the response through the income channel is negative.

If our model with a constant household income flow is correctly specified, the estimate whose identification builds on a theoretical model without considering a constant household income is mis-identified. In the latter model, the core regression equation and the corresponding OLS estimate are given by:

$$
\begin{aligned}
\Delta \alpha_{t} & \approx \rho \Delta w_{t}+\varepsilon_{t}, \\
\tilde{\rho} & =\left[\left(\Delta w_{t}\right)^{\prime}\left(\Delta w_{t}\right)\right]^{-1}\left(\Delta w_{t}\right)^{\prime}\left(\Delta \alpha_{t}\right) .
\end{aligned}
$$

However, if Eq. (2.4) is correctly specified, we will have:

$$
\mathbb{E}(\tilde{\rho})=\left[\left(\Delta w_{t}\right)^{\prime}\left(\Delta w_{t}\right)\right]^{-1}\left(\Delta w_{t}\right)^{\prime}(\rho-\theta Y) \Delta w_{t}=\rho-\theta Y \leq \rho
$$

The mis-identification problem arises when the estimate of $(\rho-\theta Y)$ is ascribed to be the estimate of $\rho$. From Eq. (2.6), if household income has a strong impact, i.e., $\theta Y$ is large, $\tilde{\rho}$, may be close to zero or negative even though the true value of $\rho$ is still positive. In other words, $\tilde{\rho}$ being close to zero or negative does not necessarily imply that micro-data does not support the existence of habit formation preferences, because it does not necessarily mean that $\rho$ is negative or zero.

\subsection{Heterogenous Responses and An External Mis-identification Problem}

Households are heterogenous in terms of the responses of their risky asset shares to wealth fluctuations through the habit channel. When households do not have large negative income shocks, they increase their risky asset shares as the optimal response to wealth accumulations through the habit channel. However, when households have large negative income shocks, 
they may decrease their risky asset shares as the optimal response to wealth accumulations through the habit channel. To see the heterogenous responses, note that when $Y$ is timevarying, the solution to $\alpha_{t}^{*}$ through the habit channel is given by

$$
\alpha \underbrace{\left[1-\frac{X}{\left(W_{t}-C_{t}+Y_{t}+\frac{Y_{t}-Y}{Z+R_{f}}\right) R_{f}}\right]\left[1+\frac{Y_{t}-Y}{\left(W_{t}-C_{t}+Y_{t}\right)\left(Z+R_{f}\right)}\right]}_{\text {The habit channel }} .
$$

Eq. (2.7) shows that if $Y_{t}$ is far below $Y$, i.e., a large negative income shock, the response through the habit channel can be negative. Note that if $Y_{t}$ is a quite persistent process, for example, $\kappa=0.95$, the value of $Z$ is about 0.05 . In this example, it is likely that the sum in the second parenthesis in the expression (2.7) becomes negative. In other words, the conventional wisdom, that risky asset shares are increasing in wealth through the habit channel, may break down in the presence of large negative income shocks.

Thus, there are two groups of households. Households in the first group have large negative income shocks and respond negatively to wealth accumulations through the habit channel. Households in the second group do not have large negative income shocks and they may respond positively. If we run regressions with a sample that pools the two different groups together, the associated estimate is mis-identified and it is likely to be insignificant. We label this mis-identification problem as the external mis-identification problem.

\subsection{Testable Predictions}

We have shown that incorporating realistic feature of time-varying household income matters in terms of identification. We now derive empirical tests of the relevance of habit formation preferences by controlling the impact of constant household income and/or income shocks, i.e., testing the weak form and the semi-strong form of HFPI. 


\subsubsection{Weak Form of HFPI}

Given the aforementioned internal and external mis-identification problems, we design the following test to examine the weak form of HFPI. We divide households in each subsample into two groups: households in the first group experienced large negative income shocks and households in the second group did not experience large negative income shocks. Second, for each group, we obtain an estimate of $\rho^{i}, i=1,2$ from equation (2.4). Third, our testable hypothesis for habit formation preference is,

$$
\rho^{2}>\rho^{1}
$$

Thus, instead of testing whether $\rho>0$ with the pooled subsamples as in Brunnermeier and Nagel (2008), we test the difference of $\rho$ 's across groups.

\subsubsection{Semi-strong Form of HFPI}

Given the aforementioned internal mis-identification problem, we run regression to obtain the estimates of the response through the habit channel, $\rho$. We consider the following testable hypothesis to test the semi-strong form of HFPI:

$$
\rho>0
$$

This is the same as in Brunnermeier and Nagel (2008). One way to understand Inequality (2.9) is: when household income is no (or small), i.e., $Y=0(Y \approx 0)$, the partial derivative of $\alpha_{t}$ with respect to $w_{t}$ is positive.

\section{Variables, Data, and Sample Selection}

Here we give a brief introduction about variables, data, and sampling. We follow closely Brunnermeier and Nagel (2008). Risk-free assets are defined as the sum of cash-like assets 
and holdings of bonds. Liquid assets are given by the sum of risk-free assets and the holdings of stocks and mutual funds. Subtracting other liabilities from liquid assets yields liquid wealth. Financial wealth are the sum of liquid wealth, equity in a private business, and home equity. We consider three different risky asset shares: the sum of the holdings of stocks and mutual funds divided by liquid wealth, the holdings of risky assets divided by financial wealth, and the sum of the holdings of stocks, mutual funds, and the equity in a private business divided by the difference between financial wealth and home equity.

The PSID panel data record many household characteristics annually after 1997 and households' asset holdings in years 1984, 1989, 1994, 1999, 2001, and 2003. Thus, timeseries data about asset holdings are either 2-year apart or 5-year apart. Hence, we divide the data into two subsamples: the 1984-1999 $(k=5)$ subsample and the 1999-2003 $(k=2)$ subsample. We select households who hold at least $\$ 10,000$ liquid wealth or at least $\$ 10,000$ financial wealth in the last period, $t-k$. In addition, we require that the martial status of the family unit head remained unchanged from $t-k$ to $t$ and that no assets were moved in or out as a consequence of a family member moving into or out of family unit.

\section{Empirical Results about Weak Form of HFPI}

To test our hypothesis, Inequality (2.8), we divide the subsample into two groups. In the first group, $i=1$, households' current income is below a threshold ratio of their time-series averages. The rest enters the second group, $i=2$. In the benchmark exercise, we set the threshold ratio at 30\%. In the sensitivity analysis, we change the ratio from $20 \%$ to $50 \%$. For each group, we estimate the following equation :

$$
\Delta_{k} \alpha_{t}=\beta^{i} q_{t-k}^{i}+\gamma \Delta_{k} h_{t}^{i}+\rho^{i} \Delta_{k} w_{t}^{i}-\vartheta y_{t}^{i} \Delta_{k}\left(w_{t}^{i}\right)+\varepsilon_{t}^{i}, i=1,2
$$

$q_{t-k}^{i}$ is a vector of household characteristics and the fixed time effects for the $i-t h$ group. For example, it includes a broad range of variables related to the life cycle, background, and 
financial situation of the household. The vector $\Delta_{k} h_{t}^{i}$ contains variables that capture major changes in household characteristic or asset ownership for the $i-t$ group. For example, it includes: changes in family size, changes in the number of children, and sets of dummies for house ownership, business ownership, and nonzero labor income at $t$ and $t-k{ }^{4}$ The inclusion of these additional variables serves the purpose of controlling some important econometric issues, such as life-cycle effects and preference shifters, and idiosyncratic versus aggregate wealth changes.

Finally, $y_{t}=\log \left(Y_{t}\right)$. In our empirical analysis of liquid risky asset shares, we use two different types of household income: the first is the total income which includes the income from liquid wealth; and the second is labor income. Note that, neither of the two is right household income which is corresponding to liquid wealth. We use the aforementioned two because we do not have the data for the right household income in line with liquid wealth. In our empirical analysis of financial risky asset shares, household income refers to labor income.

It is worth mentioning that Eq. (4.1) is not exactly in line with the theoretical model because $\rho$ depends on $y_{t}$ in the theoretical model and it is not a function of $y_{t}$ in the regression equation. Here we take three steps to show the link between our estimate from Eq. (4.1) and the $\rho$ in Eq. (2.4). To save notations, we drop the superscript $i$ in the discussion below. First, from Eq. (2.3), we have:

$$
\left.\frac{\partial \alpha_{t}^{*}}{\partial w_{t}}\right|_{Y=1}=\rho-\frac{W}{(W+1)^{2} R_{f}}
$$

where $W$ denotes the average of wealth. Second, from Eq. (5.1), we have:

$$
\left.\frac{\partial \hat{\alpha}_{t}}{\partial w_{t}}\right|_{y_{t}=0}=\hat{\rho}-\left.\hat{\vartheta} \frac{\partial y_{t} \Delta w_{t}}{\partial w_{t}}\right|_{y_{t}=0}=\hat{\rho}-\left.\hat{\vartheta} \frac{\partial y_{t} w_{t}}{\partial w_{t}}\right|_{y_{t}=0}=\hat{\rho}
$$

\footnotetext{
${ }^{4}$ In particular, asset composition controls for the liquid asset share include: the labor income/liquid wealth ratio interacted with age, the business wealth/liquid wealth ratio, and the housing wealth/liquid wealth ratio. For the financial asset share, asset composition controls consist only of the labor income/financial wealth ratio interacted with age.
} 
where $\hat{\rho}$ is the estimate from our regression equation. Last, it immediately follows that our estimate, $\hat{\rho}$, slightly underestimates $\rho$ with the difference of $\frac{e^{w}}{\left(e^{w}+1\right)^{2} R_{f}}$. With the data moments, we have the following:

$$
\rho=\hat{\rho}+\frac{W}{(W+1)^{2} R_{f}} \cong \hat{\rho}
$$

To see that the approximation holds, we check the average of wealth. In this paper, we have two types of wealth, liquid wealth and financial wealth. In the 1984-1999 subsample, the average of liquid wealth of stock market participants is $\$ 269,609$ and the average of financial wealth of stock market participants is $\$ 630,488$. In the 1999-2003 subsample, they are $\$ 294,622$ and $\$ 640,382$, respectively. With any one of these averages, the difference is close to zero given that annual risky free rates are around $3 \%$ in the periods covered by our two subsamples. The same conclusion holds for each group in each subsample.

The main results about weak form of HFPI are in Table 1. To facilitate comparison, we present the test results about the strong form of HFPI in Table 3 in which we replicate those in Tables 4 and 5 in Brunnermeier and Nagel (2008). Our results about the stock market participation and instrumental variables are close to those in Brunnermeier and Nagel (2008) thus we do not report the corresponding results. Instead, we focus on reporting results on the response of risky shares to wealth fluctuations which is corresponding to Tables 4 and 5 in Brunnermeier and Nagel (2008).

With the OLS estimates, the response of risky asset shares to wealth fluctuations in the first group is smaller than the response in the second group and the difference is statistically significant. For example, the difference between $\rho$ across groups could be 0.3 percentage points if we use liquid risky asset shares. This number seems arguably economic significant. This finding provides positive evidence of habit formation preferences in the households' portfolio choice data. Even though the 2SLS estimates are not statistically significant, they clearly imply a positive movement of $\rho$ 's from the $i=1$ group to the $i=2$ group. This is also in line with our hypothesis. The major reason for the insignificant 2SLS regression 
results is that the instruments we chose are weak instruments. That is a limitation, as we have not been able to find good instruments. One thing worth mentioning is that our practice of using labor income to denote the income from sources other than liquid wealth seems to be problematic. For this purpose, we also use the household income to denote the income from sources other than liquid wealth. The results are both statistically significant and economically significant, see Table 1.

The strong positive evidence comes from our results associated financial risky asset shares. In that case, we obtain the similar results but a larger difference between $\rho$ 's across groups. In particular, the difference increases from 0.3 percentage points to at least 0.68 percentage points, which is undoubtedly economic significant. Our regression results with financial risky asset shares provide stronger positive evidence of habit formation preferences in the PSID data. One concern about the results associated with the financial risky asset shares is the inclusion of home equity because some argue that the behavior of home equity may be quite different from other risky assets. To check whether our results are robust to the inclusion of home equity, we construct the third risky asset share by taking away home equity from both the nominator and denominator of the financial risky asset share. In that case, we obtain even stronger positive evidence of habit formation preferences in the PSID data.

In our sensitivity analysis, we change the $30 \%$ threshold value from $20 \%$ to $50 \%$ and we obtain the similar positive evidence of habit formation preferences, see Fig. 1. Panel (a) denotes the results associated with liquid risky asset share. And Panel (b) denotes the results associated with financial risky asset share. In each panel, the horizontal axis represents the value we set for the threshold ratio that is used to divide the sample into two groups. The vertical axis represents the difference between $\rho^{2}$ and $\rho^{1}$. In particular, if $\rho^{i}$ is not statistically different from zero, we set it at zero. OLS1 denotes the differences associated with our first OLS estimates in our tables. OLS2 denotes the differences associated with our second OLS estimates in our tables. All the results hold at the $10 \%$ significant confidence interval.

In summary, our hypothesis essentially implies that when habits are roughly constant, 
controlling the impact of household income and income shocks will help generate a positive increase of $\rho$ from the $i=1$ group to the $i=2$ group. Since our empirical results confirm such a hypothesis, we argue, in terms of the testable theoretical prediction, that habit formation preferences are supported by the PSID data.

\section{Empirical Results about Semi-strong Form of HFPI}

To test the prediction, Inequality (2.9), we estimate the following equation for both subsamples:

$$
\Delta_{k} \alpha_{t}=\beta q_{t-k}+\gamma \Delta_{k} h_{t}+\rho \Delta_{k} w_{t}-\vartheta y_{t} \Delta_{k} w_{t}+\varepsilon_{t}
$$

Comparing to Eq. (10) in Brunnermeier and Nagel (2008), we introduce the term $\Delta y_{t}\left(w_{t}\right)$ in Eq. (5.1) in order to get the estimate of $\rho$. The main reason is that it is not feasible to directly test $\rho>0$ because both $\rho$ and $\theta y$ are constant and there is no way to isolate the value of $\rho$ directly. Since the additional term is the only difference between Eq. (5.1) and Eq. (10) in Brunnermeier and Nagel (2008), all econometric issues, such as measurement errors, that have been addressed in Brunnermeier and Nagel (2008) are handled in the same way. As in the case of the discussion about the weak form of HFPI, we use two different types of household income in our empirical analysis of liquid risky asset shares. We use labor income to denote household income in our empirical analysis of financial risky asset shares.

The main results are in Table 2. In general, we find no response of risky asset shares to wealth fluctuations. For example, the liquid risky asset share decreases with liquid wealth in the 1984-1999 subsample and has no response in the 1999-2003 subsample. The financial risky asset share presents no response to financial wealth in both subsamples. In contrast, Brunnermeier and Nagel (2008) find strong negative response of the financial risky asset share to the wealth fluctuations. This comparison shows that controlling for income raises the estimate of $\rho$, confirming the implication of our theoretical model with constant household 
income that omitting household income bias downward the estimates of $\rho$.

Furthermore, Wachter and Yogo (2010) argue that the response of risky asset share to wealth fluctuations should be positive and it is actually in line with the negative response in Brunnermeier and Nagel (2008) once the impact of household income is considered. Our results indicate that, even though the introduction of household income may, theoretically, help explain the negative results found in Brunnermeier and Nagel (2008), the impact of household income on the relationship is too weak to reconcile the opposite relationships. That is to say, simple controlling the impact of household income alone is not enough to turn the relationship from negative to positive.

In summary, without considering the impact of large negative income shocks, empirical results are likely to reject the hypothesis, Inequality (2.9). This is because such estimates are subject to the external mis-identification problem.

\section{Conclusion}

In this paper, we introduce time-varying household income, an empirically important element, into a portfolio choice model with external habits. The key theoretical contribution of our paper is that our analytical solution adds the following new results to the literature: (1) risky asset shares respond to wealth fluctuations through two channels, habit and household income; (2) households, depending on whether they experience large negative income shocks or not, have opposite response through the habit channel; and (3) an internal mis-identification problem arises if the two channels are considered as one channel while an external mis-identification problem arises if the heterogeneous responses across households are ignored.

Accordingly, we test the semi-strong form and the weak form of HFPI. Our empirical contribution is that we find positive evidence of the weak form of HFPI. Our positive evidence of the weak form of HFPI is clear evidence of the empirical relevance of habit formation preferences in the household level data. Our refined results provide confidence with respect 
to the use of habit formation preferences in those macro models. Even though our results reject the semi-strong form of HFPI, in line with the rejection of the strong form of HFPI in the literature, our acceptance of the weak form shows the importance of controlling for the internal and external mis-identification problems. In addition, our analysis bridges the gap between the success of macro models with habits and the previous negative evidence in micro data by using more realistic theoretical models to identify the estimation.

Questions still remain. First, the effect of inertia on portfolio adjustments remains unchanged from those in Brunnermeier and Nagel (2008), which casts reasonable doubt on the soundness of habit formation preferences. Thus, the strong asset allocation inertia identified in Brunnermeier and Nagel (2008) remains an interesting and not well-understood phenomenon. Second, new data have been issued. It is of interest to check the robustness with additional data and this is on our future research agenda. 


\section{References}

Boldrin, M., Christiano, L. J., Fisher, J. D. M., 2001. Habit persistence, asset returns, and the business cycle. American Economic Review 91 (1), 149-166.

Brunnermeier, M. K., Nagel, S., 2008. Do wealth fluctuations generate time-varying risk aversion? Micro-evidence from individuals' asset allocation. American Economic Review $98(3), 713-736$.

Campbell, J. Y., Cochrane, J. H., 1999. By force of habit: A consumption-based explanation of aggregate stock market behavior. Journal of Political Economy 107 (2), 205-251.

Carrasco, R., Labeaga, J. M., Lopez-Salido, J. D., 2007. Consumption and Habits: Evidence from Panel Data. The Economic Journal 115 (1), 144-165.

Christiano, L. J., Eichenbaum, M., Evans, C. L., 2005. Nominal rigidities and the dynamic effects of a shock to monetary policy. Journal of Political Economy 113 (1), 1-45.

Dynan, K. E., 2000. Habit Formation in Consumer Preferences: Evidence from Panel Data. American Economic Review 90 (3), 391-406.

Fuhrer, J. C., 2000. Habit Formation in Consumption and Its Implications for MonetaryPolicy Models. American Economic Review 90 (3), 367-390.

Ravina, E., 2007. Habit Persistence and Keeping Up with the Joneses:Evidence from Micro Data. NYU Working Paper No. FIN-05-046.

Ravn, M., Schmitt-Grohe, S., Uribe, M., 2006. Deep habits. Review of Economic Studies 73 (1), 195-218.

Samuelson, P. A., 1969. Lifetime Portfolio Selection by Dynamic Stochastic Programming. The Review of Economics and Statistics 51 (3), 239-246.

Shore, S. H., White, J. S., 2002. External Habit Formation and the Home Bias Puzzle.

Uribe, M., 2002. The Price-consumption Puzzle of Currency Pegs. Journal of Monetary Economics 49 (3), 533-569.

Wachter, J. A., Yogo, M., 2010. Why do household portfolio shares rise in wealth? Review of Financial Studies 23 (11), 3929-3965. 


\section{A Weak Form of HFPI}

Table 1: Changes in Risky Asset Shares: Weak Form of HFPI

\begin{tabular}{|c|c|c|c|}
\hline & \multicolumn{3}{|c|}{$\mathrm{k}=5(1984-1999)$} \\
\hline & OLS1 & OLS2 & TSLS \\
\hline \multicolumn{4}{|c|}{ Dependent variable: } \\
\hline \multicolumn{4}{|c|}{ Proportion of liquid wealth invested in stocks and mutual funds } \\
\hline \multicolumn{4}{|c|}{ Key independent variable ${ }^{a}$} \\
\hline \multicolumn{4}{|c|}{$\Delta_{k} \log$ liquid wealth $t$} \\
\hline \multicolumn{4}{|c|}{ Estimates for Different Cohorts } \\
\hline Bottom $30 \%$ & $-.304^{*}$ & -.268 & -.185 \\
\hline The rest & -.160 & -.205 & .694 \\
\hline \multicolumn{4}{|c|}{ Dependent variable: } \\
\hline \multicolumn{4}{|c|}{ Proportion of liquid wealth invested in stocks and mutual funds } \\
\hline \multirow{2}{*}{\multicolumn{4}{|c|}{$\begin{array}{l}\text { Key independent variable } \\
\Delta_{k} \text { log liquid wealth } \\
t\end{array}$}} \\
\hline & & & \\
\hline \multicolumn{4}{|c|}{ Estimates for Different Cohorts } \\
\hline Bottom 30\% & $-.522^{* *}$ & $-.507 * *$ & .478 \\
\hline The rest & -.145 & $-.275^{*}$ & .721 \\
\hline \multicolumn{4}{|c|}{ Dependent variable: } \\
\hline \multicolumn{4}{|c|}{$\begin{array}{l}\text { Proportion of financial wealth invested in stocks, mutual funds, } \\
\text { equity in a private business, and home equity }\end{array}$} \\
\hline \multicolumn{4}{|c|}{ Key independent variable ${ }^{a}$} \\
\hline \multicolumn{4}{|c|}{$\Delta_{k} \log$ financial wealth $t$} \\
\hline \multicolumn{4}{|c|}{ Estimates for Different Cohorts } \\
\hline Bottom 30\% & $-.967^{* *}$ & $-.681 *$ & .312 \\
\hline The rest & -0.244 & -.374 & .487 \\
\hline \multicolumn{4}{|c|}{ Dependent variable: } \\
\hline \multicolumn{4}{|c|}{$\begin{array}{l}\text { Proportion of financial wealth (home equity not included) invested } \\
\text { in stocks, mutual funds, and equity in a private business }\end{array}$} \\
\hline \multicolumn{4}{|c|}{ Key independent variable } \\
\hline \multicolumn{4}{|c|}{$\Delta_{k} \log$ financial wealth (home equity not included) $t$} \\
\hline \multicolumn{4}{|c|}{ Estimates for Different Cohorts } \\
\hline Bottom 30\% & $-1.000 * *$ & $-1.079 * *$ & -1.105 \\
\hline The rest & -.537 & -.736 & .157 \\
\hline
\end{tabular}

Notes: Heteroskedasticity- and autocorrelation-robust standard errors are used to judge the significance of estimates. ${ }^{* *}$ denotes the estimate is statistically significantly different from 0 at the $5 \%$ significance level and * denotes that the estimate is statistically different from 0 at the $10 \%$ significance level. ${ }^{a}$ means that the included income is the labor income and ${ }^{b}$ means the income is the household income. The control variables are the same as those in Table 2. The difference between the OLS1 and the OLS2 is that only OLS2 includes "Asset composition controls" in the control variables. In particular, asset composition controls for the liquid asset share include: the labor income/liquid wealth ratio interacted with age, the business wealth/liquid wealth ratio, and the housing wealth/liquid wealth ratio. For the financial asset share, asset composition controls consist only of the labor income/financial wealth ratio interacted with age.

$$
\Delta_{k} \alpha_{t}=\beta^{i} q_{t-k}^{i}+\gamma \Delta_{k} h_{t}^{i}+\rho^{i} \Delta_{k} w_{t}^{i}-\vartheta y_{t}^{i} \Delta_{k}\left(w_{t}^{i}\right)+\varepsilon_{t}^{i}, i=1,2
$$




\section{B Semi-Strong Form of HFPI}

Table 2: Changes in Risky Asset Shares

\begin{tabular}{|c|c|c|c|c|c|c|}
\hline & \multicolumn{3}{|c|}{$\mathrm{k}=5(1984-1999)$} & \multicolumn{3}{|c|}{$\mathrm{k}=2(1999-2003)$} \\
\hline & OLS1 & OLS2 & TSLS & OLS1 & OLS2 & TSLS \\
\hline \multicolumn{7}{|c|}{ Dependent variable: } \\
\hline \multicolumn{7}{|c|}{ Proportion of liquid wealth invested in stocks and mutual funds } \\
\hline \multicolumn{7}{|c|}{ Explanatory variables ${ }^{a}:$} \\
\hline$\Delta_{k} \log$ liquid wealth $t$ & $\begin{array}{c}-.223^{* *} \\
(.114)\end{array}$ & $\begin{array}{l}-.216 \\
(.121)\end{array}$ & $\begin{array}{c}.178 \\
(.586)\end{array}$ & $\begin{array}{c}.043 \\
(.108)\end{array}$ & $\begin{array}{c}.007 \\
(.109)\end{array}$ & $\begin{array}{c}-.283 \\
(1.073)\end{array}$ \\
\hline Asset composition controls & & $\sqrt{ }$ & & & $\sqrt{ }$ & \\
\hline Preference shifters & $\sqrt{ }$ & $\sqrt{ }$ & $\sqrt{ }$ & $\sqrt{ }$ & $\sqrt{ }$ & $\sqrt{ }$ \\
\hline Life-cycle controls & $\sqrt{ }$ & $\sqrt{ }$ & $\sqrt{ }$ & $\sqrt{ }$ & $\sqrt{ }$ & $\sqrt{ }$ \\
\hline Year-region FE & $\sqrt{ }$ & $\sqrt{ }$ & $\sqrt{ }$ & $\sqrt{ }$ & $\sqrt{ }$ & $\sqrt{ }$ \\
\hline Adj. $R^{2}$ & .05 & .05 & - & .05 & .05 & - \\
\hline Overidentification test & - & - & {$[.60]$} & - & - & {$[.03]$} \\
\hline $\mathrm{N}$ & 1,184 & 1,184 & 1,189 & 1,348 & 1,348 & 1,436 \\
\hline \multicolumn{7}{|c|}{ Dependent variable: } \\
\hline \multicolumn{7}{|c|}{ Proportion of liquid wealth invested in stocks and mutual funds } \\
\hline \multicolumn{7}{|c|}{ Explanatory variables ${ }^{b}:$} \\
\hline$\Delta_{k} \log$ liquid wealth $t$ & $\begin{array}{c}-.300^{* * *} \\
(.104)\end{array}$ & $\begin{array}{c}-.384^{* *} \\
(.112)\end{array}$ & $\begin{array}{c}.441 \\
(.572)\end{array}$ & $\begin{array}{c}.010 \\
(.093)\end{array}$ & $\begin{array}{l}-.008 \\
(.094)\end{array}$ & $\begin{array}{c}-.532 \\
(1.013)\end{array}$ \\
\hline Asset composition controls & & $\sqrt{ }$ & & & $\sqrt{ }$ & \\
\hline Preference shifters & $\sqrt{ }$ & $\sqrt{ }$ & $\sqrt{ }$ & $\sqrt{ }$ & $\sqrt{ }$ & $\sqrt{ }$ \\
\hline Life-cycle controls & $\sqrt{ }$ & $\sqrt{ }$ & $\sqrt{ }$ & $\sqrt{ }$ & $\sqrt{ }$ & $\sqrt{ }$ \\
\hline Year-region FE & $\sqrt{ }$ & $\sqrt{ }$ & $\sqrt{ }$ & $\sqrt{ }$ & $\sqrt{ }$ & $\sqrt{ }$ \\
\hline Adj. $R^{2}$ & .05 & .06 & - & .04 & .05 & - \\
\hline Overidentification test & - & - & {$[.67]$} & - & - & {$[.04]$} \\
\hline $\mathrm{N}$ & 1,236 & 1,236 & 1,241 & 1,454 & 1,454 & 1,551 \\
\hline
\end{tabular}

\begin{tabular}{|c|c|c|c|c|c|c|}
\hline \multicolumn{7}{|c|}{$\begin{array}{l}\text { Dependent variable: } \\
\text { Proportion of financial wealth invested in stocks, mutual funds, } \\
\text { equity in a private business, and home equity }\end{array}$} \\
\hline \multicolumn{7}{|c|}{ Explanatory variables ${ }^{a}:$} \\
\hline$\Delta_{k} \log$ financial wealth $t$ & $\begin{array}{l}-.514 \\
(.347)\end{array}$ & $\begin{array}{l}-.465 \\
(.406)\end{array}$ & $\begin{array}{c}.343 \\
(.835)\end{array}$ & $\begin{array}{l}-.390 \\
(.248)\end{array}$ & $\begin{array}{l}-.393 \\
(.245)\end{array}$ & $\begin{array}{c}-.204 \\
(1.556)\end{array}$ \\
\hline Asset composition controls & & $\sqrt{ }$ & & & $\sqrt{ }$ & \\
\hline Preference shifters & $\sqrt{ }$ & $\sqrt{ }$ & $\sqrt{ }$ & $\sqrt{ }$ & $\sqrt{ }$ & $\sqrt{ }$ \\
\hline Life-cycle controls & $\sqrt{ }$ & $\sqrt{ }$ & $\sqrt{ }$ & $\sqrt{ }$ & $\sqrt{ }$ & $\sqrt{ }$ \\
\hline Year-region FE & $\sqrt{ }$ & $\sqrt{ }$ & $\sqrt{ }$ & $\sqrt{ }$ & $\sqrt{ }$ & $\sqrt{ }$ \\
\hline Adj. $R^{2}$ & .13 & .13 & - & .10 & .10 & \\
\hline Overidentification test & - & - & {$[.45]$} & - & - & {$[.05]$} \\
\hline $\mathrm{N}$ & 1,206 & 1,206 & 1,211 & 1,379 & 1,379 & 1,471 \\
\hline
\end{tabular}

Notes: Heteroskedasticity- and autocorrelation-robust standard errors are reported in parentheses, and p-values in brackets. ** denotes the estimate is statistically significantly different from 0 at the $5 \%$ significance level and $*$ denotes that the estimate is statistically different from 0 at the $10 \%$ significance level. ${ }^{a}$ means that the included income is the labor income and ${ }^{b}$ means the income is the household income. The control variables are the same as those in Table 2. The difference between the OLS1 and the OLS2 is that only OLS2 includes "Asset composition controls" in the control variables. In particular, asset composition controls for the liquid asset share include: the labor income/liquid wealth ratio interacted with age, the business wealth/liquid wealth ratio, and the housing wealth/liquid wealth ratio. For the financial asset share, asset composition controls consist only of the labor income/financial wealth ratio interacted with age.

$$
\Delta_{k} \alpha_{t}=\beta q_{t-k}+\gamma \Delta_{k} h_{t}+\rho \Delta_{k} w_{t}-\vartheta y_{t} \Delta_{k}\left(w_{t}\right)+\varepsilon_{t} .
$$




\section{Strong Form of HFPI: The Brunnermeier and Nagel (2008) Results}

Table 3: Changes in the Risky Asset Shares

\begin{tabular}{|c|c|c|c|c|c|c|}
\hline & \multicolumn{3}{|c|}{$\mathrm{k}=5(1984-1999)$} & \multicolumn{3}{|c|}{$\mathrm{k}=2(1999-2003)$} \\
\hline & OLS1 & OLS2 & TSLS & OLS1 & OLS2 & TSLS \\
\hline \multicolumn{7}{|c|}{ Dependent variable: } \\
\hline \multicolumn{7}{|c|}{ Proportion of liquid wealth invested in stocks and mutual funds } \\
\hline \multicolumn{7}{|c|}{ Explanatory variables: } \\
\hline \multirow[t]{2}{*}{$\Delta_{k} \log$ liquid wealth $t$} & $-.014^{*}$ & -.009 & -.012 & $.023^{*}$ & .017 & -.136 \\
\hline & $(.006)$ & $(.009)$ & $(.063)$ & $(.011)$ & $(.015)$ & $(.076)$ \\
\hline Asset composition controls & & $\sqrt{ }$ & & & $\sqrt{ }$ & \\
\hline Preference shifters & $\sqrt{ }$ & $\sqrt{ }$ & $\sqrt{ }$ & $\sqrt{ }$ & $\sqrt{ }$ & $\sqrt{ }$ \\
\hline Life-cycle controls & $\sqrt{ }$ & $\sqrt{ }$ & $\sqrt{ }$ & $\sqrt{ }$ & $\sqrt{ }$ & $\sqrt{ }$ \\
\hline Year-region FE & $\sqrt{ }$ & $\sqrt{ }$ & $\sqrt{ }$ & $\sqrt{ }$ & $\sqrt{ }$ & $\sqrt{ }$ \\
\hline Adj. $R^{2}$ & .05 & .05 & - & .01 & .02 & \\
\hline Overidentification test & - & - & {$[.41]$} & - & - & {$[.64]$} \\
\hline $\mathrm{N}$ & 1,236 & 1,236 & 1,236 & 1,455 & 1,455 & 1,455 \\
\hline \multicolumn{7}{|c|}{ Dependent variable: } \\
\hline \multicolumn{7}{|c|}{$\begin{array}{l}\text { Proportion of financial wealth invested in stocks, mutual funds, } \\
\text { equity in a private business, and home equity }\end{array}$} \\
\hline \multicolumn{7}{|c|}{ Explanatory variables: } \\
\hline$\Delta_{k} \log$ financial wealth $t$ & $\begin{array}{c}-.161^{*} \\
(.059)\end{array}$ & $\begin{array}{l}-.172 \\
(.091)\end{array}$ & $\begin{array}{c}-.198^{*} \\
(.090)\end{array}$ & $\begin{array}{c}-.108^{*} \\
(.031)\end{array}$ & $\begin{array}{c}-.103^{*} \\
(.036)\end{array}$ & $\begin{array}{r}-.355^{*} \\
(.130)\end{array}$ \\
\hline Asset composition controls & & $\sqrt{ }$ & & & $\sqrt{ }$ & \\
\hline Preference shifters & $\sqrt{ }$ & $\sqrt{ }$ & $\sqrt{ }$ & $\sqrt{ }$ & $\sqrt{ }$ & $\sqrt{ }$ \\
\hline Life-cycle controls & $\sqrt{ }$ & $\sqrt{ }$ & $\sqrt{ }$ & $\sqrt{ }$ & $\sqrt{ }$ & $\sqrt{ }$ \\
\hline Year-region FE & $\sqrt{ }$ & $\sqrt{ }$ & $\sqrt{ }$ & $\sqrt{ }$ & $\sqrt{ }$ & $\sqrt{ }$ \\
\hline Adj. $R^{2}$ & 16 & 16 & - & .06 & .06 & - \\
\hline Overidentification test & - & - & {$[.56]$} & - & - & {$[.57]$} \\
\hline $\mathrm{N}$ & 1,260 & 1,260 & 1,260 & 1,489 & 1,489 & 1,489 \\
\hline
\end{tabular}

Notes: Table 3 replicates Tables 4 and 5 in Brunnermeier and Nagel (2008). Heteroskedasticity- and autocorrelation-robust standard errors are reported in parentheses, and p-values in brackets. * denotes the estimate is statistically significant different from 0 at $5 \%$ level.

$$
\Delta_{k} \alpha_{t}=\beta q_{t-k}+\gamma \Delta_{k} h_{t}+\rho \Delta_{k} w_{t}+\varepsilon_{t} .
$$


Figure 1: Sensitivity Analysis Results

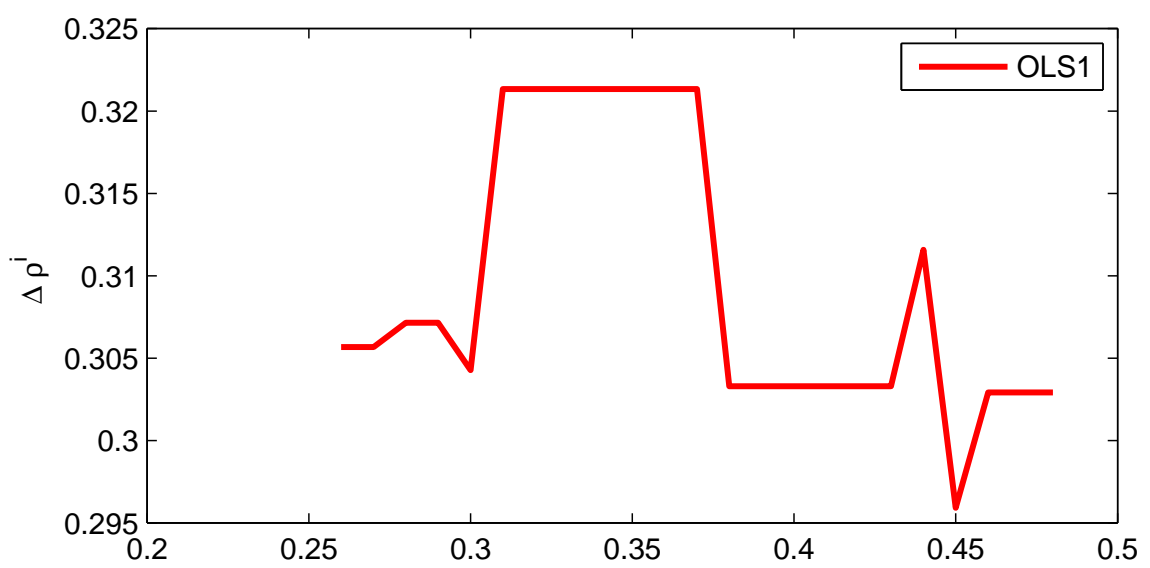

(a) Liquid Risky Asset Share: Threshold Ratio

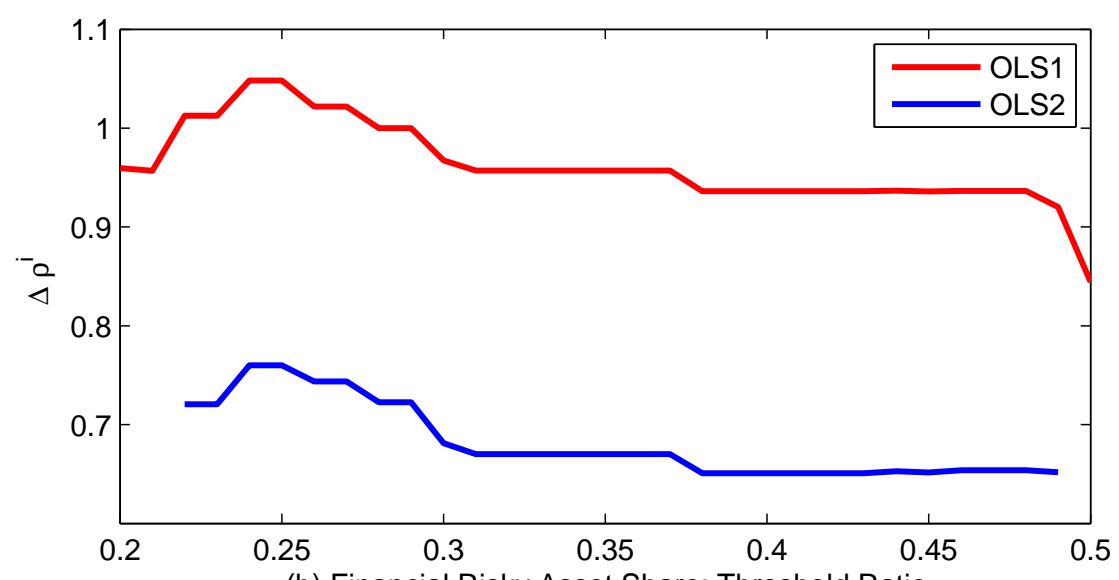

(b) Financial Risky Asset Share: Threshold Ratio

Notes: The horizontal axis represents the value we set for the threshold ratio that is used to divide the sample into two groups. The vertical axis represents the difference between $\rho^{2}$ and $\rho^{1}$. In particular, if $\rho^{i}$ is not statistically different from zero, we set it at zero. OLS1 denotes the differences associated with our first OLS estimates in our tables. OLS2 denotes the differences associated with our second OLS estimates in our tables. All the results hold at the $10 \%$ significant confidence interval. Panel (a) denotes the results associated with liquid risky asset share. Panel (b) denotes the results associated with financial risky asset share. And Panel (c) denotes the results associated with financial risky asset share without home equity. 